\title{
Lactate and Bicarbonate Uptake in the Sweat Duct of Cystic Fibrosis and Normal Subjects
}

\author{
JAN BIJMAN ${ }^{1}$ AND PAUL M. QUINTON \\ Division of Biomedical Sciences, University of California, Riverside, California 92521-0121 and Department of \\ Physiology, UCLA School of Medicine, Los Angeles, California 90024
}

\begin{abstract}
The sweat of single sweat glands of healthy individuals and cystic fibrosis patients was analyzed for differences in bicarbonate, lactate, and $\mathrm{pH}$. These values were monitored as a function of sweat rate simultaneously with 1$)$ the electrical potential difference at the duct orifice (with respect to the interstitial fluid) and 2) the concentrations of sodium, potassium, and chloride in surface sweat. Sweat in both groups contained about equal concentrations of lactate and bicarbonate at similar sweat rates. Similarly, the $\mathrm{pH}$ of sweat secreted at similar rates in the two populations was not significantly different. Acidification of sweat increased with decreasing sweat rate. In both populations, lactate and bicarbonate may be absorbed passively in the distal sweat duct in their nonionic form and, thus, not influenced by the increased electrical potential difference in the cystic fibrosis sweat duct. The uptake of these ions may involve active proton secretion by sweat duct cells. (Pediatr Res 21: 79-82, 1987)
\end{abstract}

Abbreviations

CF, cystic fibrosis

PD, electrical potential difference

$\mathrm{CF}$ is a genetically inherited disorder predominantly affecting Caucasians. Pancreatic deficiency, pulmonary disease, and elevated sweat sodium and chloride levels are the foremost manifestations that characterize the disease. Present evidence suggest that the elevated sodium and chloride concentrations in CF sweat is due to a decreased chloride permeability in the reabsorptive duct of the CF sweat gland (1-3). The altered $\mathrm{Cl}$ permeability results in a significantly larger electrical potential across the duct epithelium. A similar electrical abnormality and $\mathrm{Cl}$ impermeability has been demonstrated for airway epithelia (4). Since the distribution of electrolytes across an epithelium (or other barrier) is influenced by electrochemical potentials, the altered PD across target epithelia in CF may result in altered compositions of fluid bathing the mucosal surfaces of these tissues. Protons, $\mathrm{HCO}_{3}^{-}$ and other buffers are exceedingly important electrolytes which might be influenced by alterations in such electrical gradients and thereby be important to exocrine gland function in $\mathrm{CF}$. In this study, we compare the concentrations of $\mathrm{H}^{+}, \mathrm{HCO}_{3}{ }^{-}$, and lactate in $\mathrm{CF}$ single gland sweat with the concentrations in normal sweat as function of several parameters in sweat secretion.

Received March 14, 1986; accepted August 26, 1986.

Supported by grants from the Getty Oil Co., the Gillette Co., and NIH/USPHS AM26547.

'Present address Department of Cell Biology-1, Erasmus University Rotterdam, P.O. Box 1738, 3000 Dr. Rotterdam, The Netherlands.

\section{MATERIALS AND METHODS}

The method of sweat collection from single glands in vivo has been described in detail (1). In this study the sweat from a single sweat gland on the volar surface of the forearm of nine $\mathrm{CF}$ patients and nine control subjects was collected in serial samples over a period of $40 \mathrm{~min}$. All CF patients had a confirmed diagnosis from an established CF center. No two patients were on the same therapeutic regimen. All patients received various supplemental vitamins. All but one patient received pancreatic enzyme supplements. All but one patient received various antibiotic therapy, but no two patients were treated with the same regimen of antibiotics. Two patients did not use bronchodilator agents. All subjects were adolescents or older. The mean age of CF patients was $26.6 \pm 2.7$ (SE) yr and of normal subjects was $25.2 \pm 1.9 \mathrm{yr}$. Only one subject, a CF patient, was under $18 \mathrm{yr}$ of age. Because of the difficulty in performing a large number of $\mathrm{HCO}_{3}{ }^{-}$and lactate microassays, only one sweat gland was selected from a collection of about seven glands from each subject. The selected gland was chosen on the basis of its showing a wide range in sweat rates. That is, since we were interested largely in the concentration change as a function of rate, we selected glands which gave the greatest difference in rates and which secreted throughout the collection period (30-40 $\mathrm{min})$. The analysis of $\mathrm{Na}, \mathrm{K}$, and $\mathrm{Cl}$ in the sweat and the PD measurement were performed as described previously (1). Microvolumetric methods were used to measure bicarbonate (5) and lactate (6).

The $\mathrm{pH}$ of the sweat was measured by microfluorescence of the $\mathrm{pH}$-sensitive fluorescent dye Dextran-FITC (Sigma; $10 \mathrm{mg} /$ liter sweat). Using constant volume micropipettes (7), one volume of dye solution (approximately $2 \mathrm{nl}$ ) was added to 14 volumes of sweat (sweat dilution 7\%). The samples were collected under mineral oil between bubbles of $5 \% \mathrm{CO}_{2} 95 \% \mathrm{O}_{2}$ in constant bore microcapillaries and sealed with water saturated mineral oil which had also been equilibrated previously by bubbling with the same gas mixture for at least $1 \mathrm{~h}$. Fluorimetry of these microsamples was carried out with a Zeiss Universal " $R$ " microscope equipped with a mercury burner for epi-illumination and a Zonax controller for control of shutter speeds. The field and focus were selected as described previously (6). Samples of standards and unknowns were excited for 1-s intervals with UV light at $365 \mathrm{~nm}$. Emission was recorded as relative light intensity passed through a graded filter monochromator (Zeiss) set to a wavelength of $510 \mathrm{~nm}$. Relative intensity was a linear function $(r>0.99)$ of $\mathrm{pH}$ over the range measured ( $\mathrm{pH} 4$ to 8$)$ and was independent of the buffer used. The accuracy of the method was also validated by comparing the values of $\mathrm{pH}$ determined by microfluorescence with values determined by conventional $\mathrm{pH}$ electrodes on bulk samples of sweat collected from the body surface. The different methods generally agreed to within $0.1 \mathrm{pH}$ unit. 


\section{RESULTS}

The means of the electrical potential and of the concentrations of sodium, potassium, chloride, and residual ions are shown in Table 1 together with the time after stimulation and sweat rate for all the single gland sweat samples collected for control and $\mathrm{CF}$ individuals. As shown previously (1), the concentrations of sodium, potassium, and chloride and the PDs were significantly elevated in $\mathrm{CF}$ sweat droplets (Table 1). No difference was found in sweat rate or in the concentrations of lactate (Fig. 1) or bicarbonate (Fig. 2) between CF and control sweat at any secretory rate even though the concentration of lactate in sweat and bicarbonate also varied considerably as a function of sweat rate (Figs. 1 and 2). Since the concentration of residual ions (X), which is taken as the sum of the measured concentrations of cations minus the sum of the measured concentrations of anions, is close to zero for both control and CF sweat we surmise that the measured ions constitute the principle electrolytes in the sweat. These electrolytes probably account for the main ionic constituents of the primary sweat with insignificant contributions from other organic ions or proteins. Due to the limited quantity of sweat in the small samples, only a few samples could be analyzed for $\mathrm{pH}$, but the data obtained showed that with decreasing sweat rates (i.e. with time) the $\mathrm{pH}$ of the sweat declined from about 7.3 at high sweat rates to at least 5.5 at low sweat rates (Fig. 2).

\section{DISCUSSION}

Previous work. Previous studies (8) reported that lactate in the sweat from pooled secretions of single sweat glands obtained from a limited number of individuals ranged from $16 \mathrm{mM}$ at high sweat rates to $40 \mathrm{mM}$ at low sweat rates. We cannot explain the difference between the much lower lactate concentration that we found at low sweat rates or the opposite relationship between rate and concentration (Table 1). Using a similar technique, Kaiser et al. (9) found lactate concentrations between 10 and 24 $\mathrm{mM}$. More recently lactate measured in frontal sweat (10) was found to increase from about $11 \mathrm{mM}$ at low rates to about 21 $\mathrm{mM}$ at high rates. Similarly, frontal sweat from normal and CF children was reported (11) to contain about $16 \mathrm{mM}$ in both populations. These results agree well with those presented here from glands secreting at higher sweat rates (Table 1).

Our values on $\mathrm{pH}$ and $\mathrm{HCO}_{3}{ }^{-}$are consonant with other studies $(8,9,12,13)$, but conflict with the findings of Kaiser and Drack (14) for the $\mathrm{pH}$ and $\mathrm{HCO}_{3}{ }^{-}$of sweat from CF individuals. These investigators calculated the $\mathrm{HCO}_{3}{ }^{-}$concentration from the assumed $\mathrm{pCO}_{2}$ and measured $\mathrm{pH}$. Since their $\mathrm{HCO}_{3}{ }^{-}$and $\mathrm{pH}$ values appear high in comparison to our values and those in other studies $(8,12,13)$, an error may have occurred due to incomplete equilibration of their samples with $\mathrm{CO}_{2}$.

Possible mechanisms. The primary sweat elaborated in the secretory coil of the human sweat gland is thought to be close to isotonic with interstitial fluid so that sodium, potassium, and

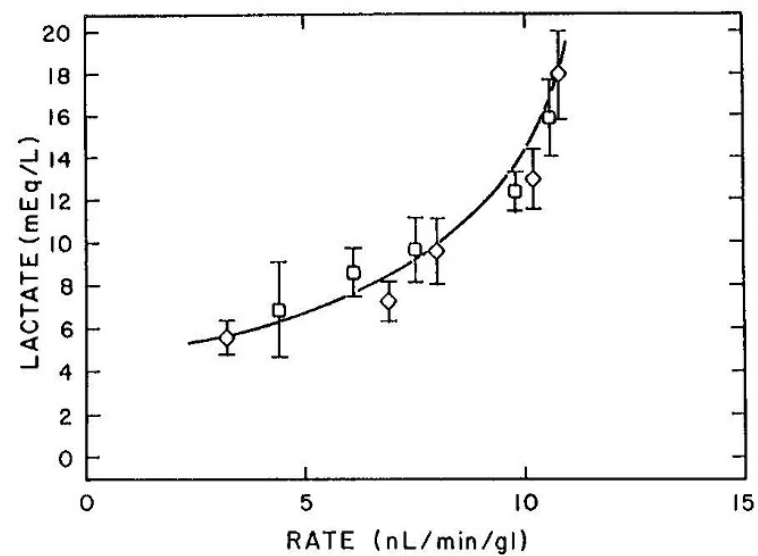

Fig. 1. Concentration of lactate as a function of secretory rate in sweat collected from single glands from $\mathrm{CF}(\diamond)$ and control $(\square)$ subjects. Analysis was performed on the same samples reported in Table 1. Curve drawn by eye. Vertical bars are SEM.

Table 1. Sweat rates, electrical potentials, and concentrations of sodium, potassium, chloride, bicarbonate, and lactate associated with the sweat of $C F$ and normal $(N)$ individuals*

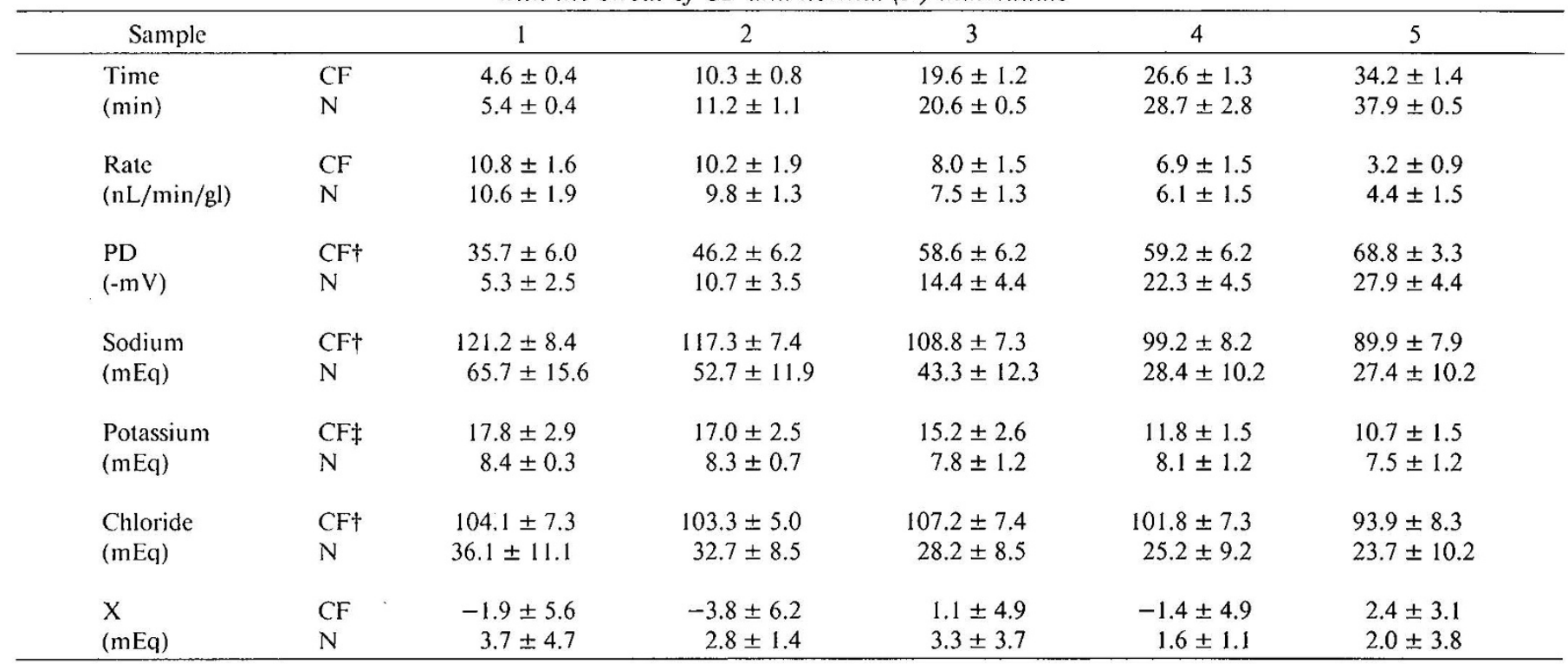

* Five serial collections of sweat from a single gland were taken at 5- to 10-min intervals. Each point represents the average ( \pm SE) of measurements of single gland sweat from seven to nine individuals (see text). The sum of anions (listed plus Figs. 1 and 2) minus the sum of listed cations represents the residual anions, $X$.

+ All values $p<0.01$.

+ All values $p<0.05$ : all other data $p>0.05$. 


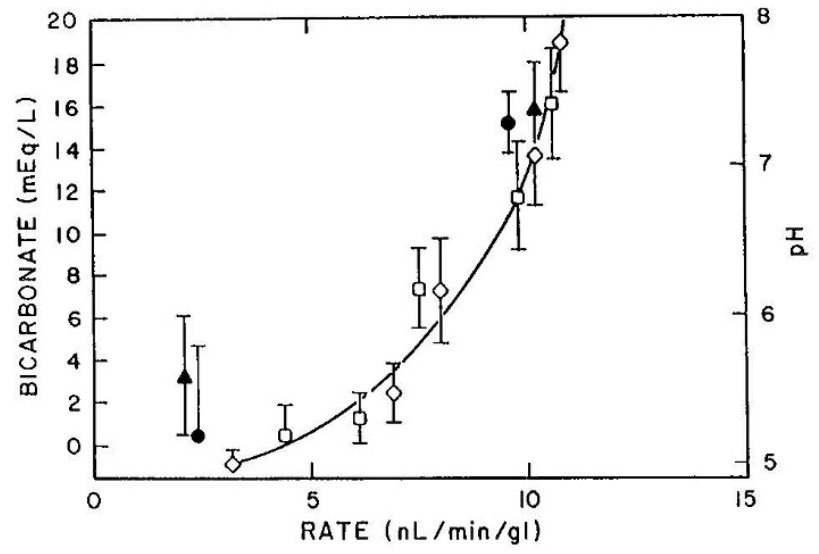

Fig. 2. Concentration of bicarbonate (left ordinate) as a function at varying secretory rates in sweat collected from single glands from $\mathrm{CF}(\diamond)$ and normal $(\square)$ subjects. The $\mathrm{pH}$ (right ordinate) is also indicated at a high and a low sweat rate for $\operatorname{CF}(\bullet)$ and normal sweat $(\triangle)$. Continuous curve fitted by eye. Vertical bars are SEM.

chloride appear in plasma-like concentrations (15-17). Bicarbonate may also be secreted at concentrations slightly less than those of the plasma $(15,16)$. Lactate is likely to be secreted by the secretory coil as a product of anaerobic oxidation (16). Uptake of sodium and chloride takes place in the sweat duct $(16,17)$ and a $\mathrm{Na} / \mathrm{H}$ exchange has been suggested to mediate the uptake of bicarbonate and possibly lactate in this part of the sweat gland $(9,18)$. The possibility of a defect in the $\mathrm{Na} / \mathrm{H}$ exchange mechanism in the CF sweat duct has been considered (14). The present results may afford more insight into the mechanisms of the transport of $\mathrm{HCO}_{3}{ }^{-}$, lactate, and protons in the sweat gland.

It is perhaps surprising, in view of the fact that $\mathrm{CF}$ sweat differs dramatically from normal in its concentration of $\mathrm{Na}, \mathrm{Cl}$, and $\mathrm{K}$ as well as in the transepithelial $\mathrm{PD}$ associated with its production $(1,3,19)$, that no significant differences were found in $\mathrm{pH}$ or in lactate and bicarbonate concentrations (Table 1). This finding, at once, suggests that the mechanism for handling these species is unaffected, or minimally affected, in CF and raises the question of what kind of mechanism might be unaffected in the face of such overt alterations in other electrolyte transport functions. We consider three classes of mechanisms which might be involved.

First, as with $\mathrm{Na}$ and $\mathrm{Cl}$ concentrations, the increased concentrations of lactate and $\mathrm{HCO}_{3}{ }^{-}$in surface sweat with increased sweat rate may be due to decreased fractional reabsorption of these components in the sweat duct. In several tissues, anion transport across the cell depends largely on the electrical gradient, the sodium gradient, or a combination of these. For example, electrodiffusive lactate (or bicarbonate) transport may take place in intestine, renal proximal tubule, or placenta (20-22). In contrast, sodium-dependent carrier-mediated lactate uptake, electrogenic or electroneutral, may take place in the renal cortical tubule and intestinal brush border membranes $(20,23)$ and rabbit cortical or rat proximal brush border membranes $(23,24)$. However, in the human sweat duct there is a significant difference in the transepithelial sodium and electrical gradients in the CF and control populations (Table 1). In the CF sweat duct both the mucosal membrane PD and $\mathrm{Na}$ gradient are greatly increased (13). Since there is no significant difference between $\mathrm{HCO}_{3}{ }^{-}$or lactate uptake in the CF gland, it seems unlikely that the above electrodiffusive or Na-dependent mechanisms play a major role in the transport of $\mathrm{HCO}_{3}{ }^{-}$or lactate in the sweat duct. Nonetheless, a sodium-dependent and $\mathrm{pH}$-independent (25) carrier-mediated lactate (or $\mathrm{HCO}_{3}{ }^{-}$) uptake would depend on the $\mathrm{Km}$ for sodium. As such, further information is needed to rule out Nacotransport uptake mechanisms.
Second, a Na-independent, voltage-independent mechanism might exist with a nonconductive pathway such as $\mathrm{Cl}^{-} / \mathrm{HCO}_{3}{ }^{-}$ exchange as described for intestine and gallbladder (26) among other epithelia. A lactate/bicarbonate $\left(\mathrm{OH}^{-}\right)$exchange has been described (27), but it is difficult to explain the role of such exchangers in the sweat duct since all three of the anions involved, $\mathrm{Cl}^{-}, \mathrm{HCO}_{3}{ }^{-}$, and lactate decrease in concentration as a function of sweat rate (Table 1), i.e. all three anions are reabsorbed. An exchanger implies that one of the components should be secreted and show a reciprocal relation between concentration and rate.

Third, it may be more likely that the uptake of bicarbonate as well as lactate in the sweat duct is a function of proton secretion. The $\mathrm{pH}$ of precursor sweat is at least 7.25 in both groups (16), so that acidification of the sweat (Fig. 2) must occur in the lumen of the sweat duct. Since the pH of the interstitial fluid is 7.4, protons are accumulated in the duct against a steep chemical gradient. This movement may occur via the direct secretion of protons into the lumen (28) or as an exchange process coupled to the downhill movement of sodium into the cells $(29,30)$. Either process should accelerate the diffusion of nonionic lactate and bicarbonate $\left(\mathrm{CO}_{2}\right)$ from the lumen. The fact that at lower sweat rates, decreased $\mathrm{pH}$ is associated with decreased lactate and $\mathrm{HCO}_{3}{ }^{-}$concentration argues for proton driven absorption of these associable anions by nonionic diffusion. While we try to guard against circular logic, the fact that the $\mathrm{pH}$ of $\mathrm{CF}$ and normal sweat does not differ (Figure 2) is also consistent with this notion.

In conclusion, present evidence suggests that there is no detectable difference in the $\mathrm{pH}$ or the sweat concentrations of bicarbonate and lactate at any sweat rate between $\mathrm{CF}$ and control groups. We suggest that these anions are reabsorbed by nonionic diffusion as a function of proton secretion into the duct, but whatever the mechanism(s) responsible for managing these anions in $\mathrm{CF}$, it is not markedly abnormal as previously suggested $(7,14)$. The simplest interpretation possible at this time may be that the sweat duct secretes protons by a mechanism which is not affected in CF (12).

Acknowledgment. The generous cooperation and patience of the volunteers who made this study possible are gratefully acknowledged.

\section{REFERENCES}

1. Bijman J, Quinton PM 1984 Influence of abnormal $\mathrm{Cl}^{-}$permeability on sweating in cystic fibrosis. Am J Physiol 247:C3-C9

2. Quinton PM 1983 Chloride impermeability in cystic fibrosis. Nature 301:421 422

3. Quinton PM, Bijman J 1983 Higher bioelectric potentials due to decreased chloride absorption in the sweat glands of patients with cystic fibrosis. $\mathrm{N}$ Engl J Med 308:1185-1189

4. Knowles MR, Stutts MJ, Spock A, Fischer N, Gatzy JT 1983 Abnormal ion permeation through cystic fibrosis respiratory epithelium. Science 221:10671070

5. Atkinson E, Quinton PM $1982 \mathrm{HCO}_{3}$ assay by $\mathrm{x}$-ray analysis. Anal Chem 54:791-793

6. Hannon D, Quinton PM 1984 Ultramicro assay of lactate by fluorescence microscopy. Anal Chem 56:2350-2351

7. Quinton PM 1976 Construction of pico-liternano-liter self-filling volumetric pipettes. Am J Physiol 40:260-262

8. Emrich HM, Stoll E, Friolet B, Colombo JP, Richterich R, Rossi E 1968 Sweat composition in relation to rate of sweating in patients with cystic fibrosis of the pancreas. Pediatr Res 2:464-478

9. Kaiser D. Williams RS, Drack E 1974 Hydrogen ion and electrolyte excretion of the single human sweat gland. Pflugers Arch 349:63-72

10. Fellmann N, Grizard G, Coudert J 1983 Human frontal sweat rate and lactate concentration during heat exposure and exercise. J Appl Physiol 54:355-360

11. Labbe A, Fellmann N, Gachon AM, Coudert J 1984 Lactate concentration in thermal sweat from children with cystic fibrosis. In: Lawson D (ed) Cystic Fibrosis: Horizons. John Wiley and Sons, New York, p 330

12. Nikolajek WP, Emrich HM $1976 \mathrm{pH}$ of sweat of patients with cystic fibrosis. Klin Wochenschr 54:287-288

13. Reddy MM, Quinton PM 1986 Intracellular microelectrode analysis of chloride transport in normal and cystic fibrosis human reabsorptive sweat duct. Biophys J 49:157a 
14. Kaiser D, Drack E 1974 Diminished excretion of bicarbonate from the single sweat gland of patients with cystic fibrosis of the pancreas. Eur J Clin Invest $4: 261-267$

15. Sato K 1977 The physiology, pharmacology, and biochemistry of the eccrine sweat gland. Rev Physiol Biochem Pharmacol 79:588-607

16. Sato K 1982 Mechanisms of eccrine sweat secretion. In: Quinton PM, Martinez JR, Hopfer U (eds) Fluid and Electrolyte Abnormalities in Exocrine Glands in Cystic Fibrosis. San Francisco Press Inc., San Francisco, pp 35-52

17. Schulz. IJ 1969 Micropuncture studies of the sweat formation in cystic fibrosis patients. J Clin Invest 48:1470-1477

18. Quinton PM 1982 Suggestion of an abnormal anion exchange mechanisms in sweat glands of cystic fibrosis patients. Pediatr Res 16:533-537

19. Bijman J, Quinton PM 1984 Apparent absence of cystic fibrosis sweat factor on ion-sclective and transport properties of the perfused human sweat duct. Pediatr Res 18:1292-1296

20. Barac-Nicto M. Murer H, Kinne R 1982 Asymmetry in the transport of lactate by basolateral and brush border membranes of rat kidney cortex. Pflugers Arch 392:366-371

21. Fromter E 1979 Solute transport across epithelia: What can we learn from micropuncture studies on kidney tubules? J Physiol 288:1031

22. Kastendieck E. Moll W 1977 The placental transfer of lactate and bicarbonate in the guinea-pig. Pflugers Arch 370:165-171
23. Storelli C, Cassano G, Hildman B, Lippe C 1980 Polar distribution of sodiumdependent and sodium-independent transport systems for L-lactate in the plasma membrane of rat enterocytes. Pflugers Arch 388:11-16

24. Nord ES, Wright ES, Kippen I, Wright EM 1982 Pathways for carboxylic acid transport by rabbit renal brush border membrane vesicles. Am J Physiol 243:F465-F466

25. Ullrich KJ, Rumrich G, Kloss S 1982 Reabsorption of monocarboxylic acids in the proximal tubule of the rat kidney. I. Transport kinetics of D-lactate, $\mathrm{Na}^{+}$-dependence, $\mathrm{pH}$-dependence and effect of inhibitors. Pflugers Arch 395:212-219

26. Ericson $\mathrm{AC}$, Spring $\mathrm{KR} 1982$ Coupled $\mathrm{NaCl}$ entry into Necturus gallbladder epithelial cells. Am J Physiol 243:C140-C145

27. Spencer TL, Lehninger AL 1976 L-Lactate transport in Ehrlich ascites-tumour cells. Biochem J 154:405-414

28. Cannon C. Adelsberg SK, Al-Awqati Q 1985 Carbon-dioxide-induced exocytotic insertion of $\mathrm{H}^{+}$pumps in turtle-bladder luminal membrane: role of cell $\mathrm{pH}$ and calcium. Nature 314:443-446

29. Kinsella JL, Aronson PS 1980 Properties of the $\mathrm{Na}^{+}-\mathrm{H}^{+}$exchanger in renal microvillus membrane vesicles. Am J Physiol 238:F461-F469

30. Murer H, Hopfer U, Kinne R 1976 Sodium/proton antiport in brush-bordermembrane vesicles isolated from rat small intestine and kidney. Biochem $\mathbf{J}$ 154:597-604 